\title{
Sarcoma de Kaposi sobre injerto renal
}

\author{
Ruibal Moldes MA, López García D, Chantada Abal V, Sánchez Rodríguez-Losada J, \\ González Martín M.
}

Servicio de Urología. Hospital Juan Canalejo. La Coruña.

Actas Urol Esp 2008:32(9):934-936

\section{RESUMEN}

SARCOMA DE KAPOSI SOBRE INJERTO RENAL

El sarcoma de Kaposi es un tumor infrecuente de causa desconocida, pero con una mayor incidencia en pacientes inmunodeprimidos, sobre todo en trasplantados y VIH positivos. Habitualmente se presenta como lesiones cutáneas de buen pronóstico, siendo la forma invasiva visceral rara, agresiva y rara su remisión.

Presentamos un paciente con un sarcoma de Kaposi a nivel del injerto renal y mala respuesta a pesar de retirar la inmunosupresión.

Palabras clave: Sarcoma de Kaposi. Trasplante renal. Inmunosupresión.

\section{ABSTRACT}

KAPOSI'S SARCOMA IN A RENAL GRAFT

Kaposi's sarcoma is an infrequent tumor of unknown cause, but with a higher impact in immune depressed individuals, particularly in HIV and transplant patients. It usually appears as a benign cutaneous lesions, while the invasive visceral form is uncommon with malignant evolution and wit rare remission.

We present a patient with a Kaposi's sarcoma localised in a renal graft and bad response even when immuno suppression was discontinued.

Keywords: Visceral Kaposi`s sarcoma. Kidney allograft. Immunosuppresion.

$\mathrm{E}$ sarcoma de Kaposi (KS) es un tumor infrecuente, de causa desconocida, compuesto de tejido fibroso y vascular, con una mayor incidencia en individuos inmunodeprimidos, sobre todo pacientes VIH y trasplantados. Generalmente se presenta como lesiones cutáneas nodulares benignas que regresan al cesar la inmunosupresión. La forma invasiva maligna visceral es infrecuente, puede comprometer cualquier órgano y son raras las remisiones.

Presentamos un paciente con KS localizado exclusivamente a nivel del injerto renal y mala evolución a pesar de la retirada de la inmunosupresión.

\section{CASO CLÍNICO}

Varón de 51 años con poliquistosis renal e insuficiencia renal que a los 3 meses de iniciar diálisis Julio de 1996) recibe injerto renal de donante cadá- ver a nivel de fosa ilíaca derecha e inmunosupresión con ciclosporina, azatioprina y prednisona. A los 6 meses del trasplante ingresa por edema y dolor en miembro inferior derecho, sin signos de tromboflebitis y función renal normal. En los estudios de laboratorio presenta: hematocrito $28 \%$, creatinina $1,23 \mathrm{mg} / \mathrm{dl}$, albúmina $2,7 \mathrm{~g} / \mathrm{dl}$, proteinuria de $1 \mathrm{~g} / 24$ $\mathrm{h}$, marcadores positivos para citomegalovirus, virus de Epstein-Barr, herpes virus 1 y negativos para herpes virus $8 \mathrm{y}$ VIH.

En la ecografía existe una discreta dilatación pielocalicial del injerto, con un flujo venoso y arterial normal. La TAC revela una lesión sólida infiltrante a nivel del hilio del injerto con moderada uropatía (Fig. 1) y que en la biopsia guiada por TAC no se demuestran células malignas. En el venograma se observa estenosis del $85 \%$ en la vena ilíaca externa a la altura de la anastomosis con la vena renal (Fig. 2).

Abreviaturas: KS: sarcoma de Kaposi. VIH: virus de inmunodeficiencia humana. TAC: tomografía axial computarizada. 


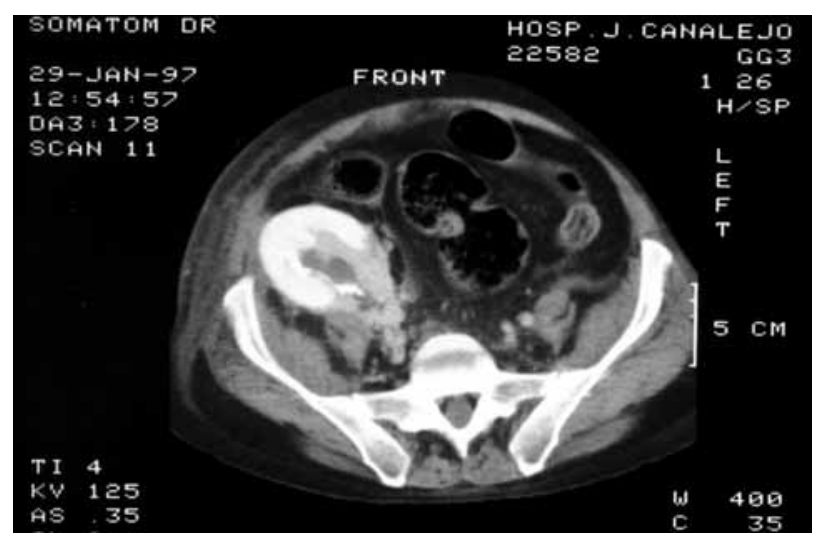

FIGURA 1. TAC abdómino-pélvico: injerto renal en fosa iliaca derecha que presenta lesión sólida infiltrante a nivel del seno renal.

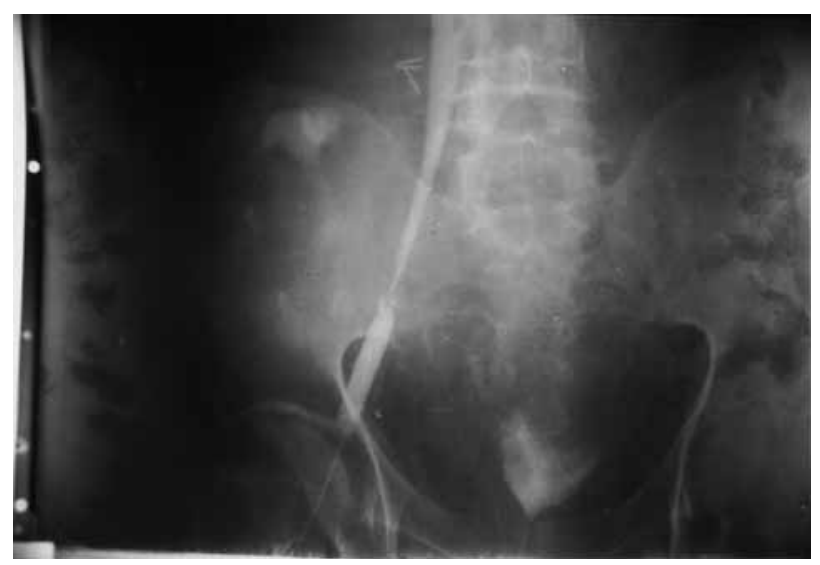

FIGURA 2. Venografia: importante reducción del calibre de la vena iliaca externa a la altura de la anastomosis con la vena del injerto renal.

En la cirugía se confirma una lesión fibrosa que infiltra seno renal y vasos ilíacos y que se logra resecar parcialmente, liberando uréter y vena ilíaca, correspondiendo la anatomía patológica a un KS. El estudio abdominal (incluyendo endoscopia digestiva) descarta afección de otros órganos. Ante estos hallazgos se propone al paciente retirar la inmunosupresión y vigilar la evolución. A los 3 meses de la cirugía y con injerto funcionante se detecta una progresión local de la enfermedad que se extiende a pared abdominal, por lo que se decide iniciar quimioterapia (doxorrubicina, vincristina y bleomicina). A pesar de mantener una función renal normal y no objetivarse lesiones a distancia, no se obtiene respuesta a nivel local, falleciendo el paciente a los 9 meses del diagnóstico por grave malnutrición y sepsis.

\section{DISCUSIÓN}

La incidencia de KS es 500 y 20000 veces mayor en receptores de un órgano sólido y VIH +, respecti- vamente, que en la población general, sugiriendo la inmunosupresión como un factor importante en el desarrollo de la enfermeda ${ }^{1}$. Aunque su patogenia es desconocida, recientes estudios han implicado al herpes virus humano tipo 8 (HHV 8) o también llamado herpes virus del KS (KSHV), detectándose su presencia en las lesiones del KS. Afecta al 0,4\% de los receptores de un injerto renal, representando el $6 \%$ de todas las neoplasias en esta población (3\% en los tratados con azatioprina y de $10 \%$ en el grupo de la ciclosporina) ${ }^{2}$. Generalmente se presenta como lesiones limitadas a la piel, siendo infrecuente la afectación visceral.

El principio de la estrategia terapéutica pasa por reducir o retirar la inmunosupresión, obteniendo una remisión de las lesiones cutáneas con el consiguiente riesgo de pérdida del injerto por rechazo ${ }^{3}$. A partir de estudios experimentales que demuestran que la ciclosporina favorece el desarrollo de neoplasias $^{4}$, entre ellas el KS por un incremento en la expresión del factor de crecimiento vascular endotelial $(\mathrm{VEGF})^{5}$, se cree que gran parte del efecto de retirada de la inmunosupresión se debe al cese de la ciclosporina. Datos procedentes del grupo de Cincinnati indican que sólo se obtiene un $17 \%$ de remisión parcial o completa al retirar la ciclosporina. Estudios recientes han obtenido una alta tasa de remisiones al sustituir la ciclosporina por el sirolimus, ya que al beneficio de la retirada de la ciclosporina se le suma el doble efecto beneficioso del sirolimus en estos pacientes: su acción antineoplásica que inhibe la progresión del KS y su acción inmunosupresora que permite preservar la función del injerto ${ }^{3,6}$. Sin embargo, todos estos hallazgos se refieren a la forma cutánea de la enfermedad, quedando por demostrar su beneficio en las formas más graves con afectación visceral. La forma maligna invasiva afecta esencialmente pulmón y aparato digestivo (aunque puede afectar cualquier órgano) y suele acompañarse de uleración cutánea y adenopatías (es infrecuente la ausencia de compromiso cutáneo). El pronóstico depende de la presencia o no de afectación visceral, siendo muy raras las remisiones cuando existe compromiso visceral.

Sólo se han comunicado dos casos con afectación del injerto renal, pero a diferencia de nuestro caso, en ambos existían lesiones cutáneas y en otros órganos además de infiltración en el parénquima renal, realizándose en ambos trasplantectomía. 
En nuestro caso, al existir infiltración de vasos ilíacos sin compromiso del parénquima renal ni lesiones a distancia y buena función del injerto, se optó por no realizar trasplantectomía y suspender la inmunosupresión. El paciente mantuvo una buena función renal sin evidencia de lesiones a distancia, pero con progresión local de la enfermedad que no respondió a la quimioterapia, falleciendo a los pocos meses por grave deterioro de su estado general y sepsis.

\section{REFERENCIA}

1. Hayward GS. Initiation of angiogenic Kaposi,s sarcoma lesions. Cancer Cell 2003;3:1-3.

2. Penn I. Cancer in cyclosporine-treated vs azatioprine-treated patients. Transplant Proc. 1996;28(2):876-878.

3. Stallone G, Schene A, Infante B, Di PaoloS, Loverre A, Maggio G, et al. Sirolimus for Kaposi,s sarcoma i renal transplant recipients. N Engl J Med. 2005;352(13):1317-1323.
4. Hoja M, Morimoto T, Mallucio M, et al. Cyclosporine induces cancer progresión by a cell autonomous mechanism. Nature 1999;397:530-534.

5. Shilab FS, Bennet WM, Yi H, Andoh TF. Expression of vascular endothelial growth factor and its receptor Flt-1 and KDR/FIK-1 in chronic cyclosporine nephrotoxicity. Transplantation 2001;72:164-168.

6. Campistol JM, Gutiérrez-Dalmau A, Vicente J. Conversión to Serolimus: a succesful treatment for posttransplantation Kaposi`s sarcoma. Transplantation 2004;77(5):760-762.

Correspondencia autor: Dr. M. Ruibal Moldes.

Servicio de Urología

Hospital Juan Canalejo.

Xubias de Arriba, 84 - 15006 La Coruña

Tel.: 981178000

E-mail: ruibalmoldes@terra.es

Información artículo: Nota clínica

Trabajo recibido: marzo 2007

Trabajo aceptado: abril 2007 